\title{
Network Entropy and Systemic Risk in Dynamic Banking Systems
}

\author{
Liang $\mathrm{He}^{1}$ and Shouwei $\mathrm{Li}^{2}$ \\ ${ }^{1}$ School of Economics, Fudan University, Shanghai 200433, China \\ ${ }^{2}$ School of Economics and Management, Southeast University, Nanjing 211189, China \\ Correspondence should be addressed to Liang He; heliangfudan@126.com
}

Received 10 July 2017; Revised 30 September 2017; Accepted 17 October 2017; Published 5 November 2017

Academic Editor: Thiago C. Silva

Copyright ( 2017 Liang He and Shouwei Li. This is an open access article distributed under the Creative Commons Attribution License, which permits unrestricted use, distribution, and reproduction in any medium, provided the original work is properly cited.

We investigate network entropy of dynamic banking systems, where interbank networks analyzed include random networks, smallworld networks, and scale-free networks. We find that network entropy is positively correlated with the effect of systemic risk in the three kinds of interbank networks and that network entropy in the small-world network is the largest, followed by those in the random network and the scale-free network

\section{Introduction}

There exist financial connections in the interbank market, which make it possible for the interbank market to be represented as a network. It is important to study the financial connections in the interbank market from the network perspective. The reason for this is that the financial connections can become a channel for propagation and amplification of shocks, which is directly linked to the stability of economic/financial systems [1]. In fact, many empirical studies have shown that interbank lending relationships reflect some typical network structures (e.g., [2-6]), such as random structures, small-world structures, and scale-free structures. And there is a rapidly growing literature on bank network models and systemic risk (e.g., [7-19]).

According to the above literature, we can know that banking systems can be modeled as the complex networks, which are useful to investigate systemic risk. In the realm of complex networks, the entropy has been adopted as a measure to characterize properties of the network topology [20-22]. However, there is limited research to adopt entropy to investigate interbank networks and systemic risk. And this paper aims to add to the current literature on understanding systemic risk in banking systems from the perspective of network entropy. The rare instance is the work of Lee [23] who applies the measure of network entropy to BIS global financial network database in order to study highly connected global banking networks. The study of Lee [23] mainly investigates how network structure of global banking networks among core countries has evolved during the global financial crisis of 2007-2009 in terms of diversification and probes into financial linkages between core countries and periphery countries. Besides, some studies show that the notion of entropy can be used to build an early warning indicator for systemic risk $[24,25]$.

Based on the above analysis, it can be seen that entropy measures have been rarely adopted to analyze interbank networks and banking systemic risk. And the single study only adopts network entropy to measure diversity of highly connected global banking networks. Besides, there are a lot of researches on adopting the entropy to investigate complex networks (e.g., $[20-22,26])$. This paper aims to contribute to investigating characteristics of network entropy of dynamic banking systems and study whether network entropy can be used as a measure of robustness for banking systems from the perspective of systemic risk.

Therefore, in this paper, we apply the measure of network entropy to the dynamic banking systems, where interbank networks analyzed include random, small-world, and scalefree networks. In the context of the analysis of interbank 
networks, we transform adjacency matrices into stochastic matrices and then apply the concept of entropy. In this paper, we find that network entropy is positively correlated with the effect of systemic risk in the three kinds of interbank networks and that network entropy in the small-world network is the largest, followed by those in the random network and the scale-free network.

The rest of the paper is organized as follows. Section 2 describes the methodology. Section 3 presents the results of numerical simulations. And the conclusion is drawn in Section 4

\section{Methodology}

2.1. Modeling of Dynamic Banking Systems. The modeling of dynamic banking systems in this paper is based on the study of Lux [27]. However, we are different in the formation of interbank lending relationships and liquidity shocks. Besides, we take bank defaults into consideration, while Lux does not. To develop a dynamic model of a banking system with $N$ banks, we start from the description of its stylized balance sheets. We assume that the assets of bank $k$ at time $t$ include investments, interbank loans, and liquid assets, denoted by $I_{k}(t), L_{k}(t)$, and $M_{k}(t)$, respectively, and that its liabilities are composed of deposits, interbank borrowing, and net worth, denoted by $D_{k}(t), B_{k}(t)$, and $W_{k}(t)$, respectively. At the initial time, we assume that the interbank market does not yet exist and set the structure of the balance sheet of bank $k$ at time $t=0$ as $I_{k}(0)=\alpha T A_{k}(0), M_{k}(0)=(1-\alpha) T A_{k}(0), W_{k}(0)=$ $\beta T I_{k}(0)$, and $D_{k}(0)=(1-\beta) T I_{k}(0)$, where $T A_{k}(0)$ and $T I_{k}(0)$ denote the total assets and the total liabilities of bank $k$ at the initial time, respectively. In the simulation, we adopt the following algorithm to determine how the banking system evolves from one state to another.

The first phase is the update of liquid assets and net worth. At the beginning of time $t$, liquid assets and net worth of bank $k$ are updated as follows:

$$
\begin{aligned}
M_{k}(t)= & M_{k}(t-1)+\left[D_{k}(t)-D_{k}(t-1)\right] \\
& -\sum_{i \in \Psi_{k}(t-1)} B_{k i}(t-1)\left[1+r_{k i}(t-1)\right] \\
& +\sum_{j \in \Phi_{k}(t-1)} b_{j k}(t-1)\left[1+r_{j k}(t-1)\right], \\
W_{k}(t)= & W_{k}(t-1)-\sum_{i \in \Psi_{k}(t-1)} b_{k i}(t-1) r_{k i}(t-1) \\
& +\sum_{j \in \Phi_{k}(t-1)} b_{j k}(t-1) r_{j k}(t-1),
\end{aligned}
$$

where $\Phi_{k}(t)$ and $\Psi_{k}(t)$ denote the set of debtors and the set of creditors of bank $k$ at time $t$, respectively. $B_{i j}(t)$ is the actual amount borrowed by bank $i$ from bank $j$, and its interest rate is $r_{i j}(t)$. In this paper, we assume that the duration of all debts is one and that banks' investments remain constant over time and disregard the return from them for simplicity. Following the study of Gatti et al. [28], we assume that the lender $j$ sets the interest rate $r_{i j}(t)$ on loans to the borrower $i$.

$$
r_{i j}(t)=\eta\left(W_{j}(t)\right)^{-\eta}+\eta\left(\delta_{i}(t)\right)^{\eta},
$$

where $\eta>0$ and $\delta_{i}(t)=B_{i}(t) / W_{i}(t)$. According to the study of Georg [29], we introduce the following shocks to deposits, which is the source of the formation of interbank credit lending relationships:

$$
D_{k}(t)=\left(1-\gamma_{k}+2 \gamma_{k} X\right) D_{k}(t-1),
$$

where $\gamma_{k}$ is a scaling parameter for the level of deposit fluctuations and $X$ is a random variable $(X \in[0,1])$.

The second phase is default settlement. After the first phase, bank $k$ defaults due to insolvency if $W_{k}(t) \leq 0$. If bank $k$ defaults, it will result in the loss of its creditors. We assume that the loss caused by the default of bank $k$ is shared proportionally by its creditor banks with their respective lending sizes. After the adjustment of liquid assets and net worth by subtracting the loss, a creditor bank of bank $k$ also defaults if its net worth is less than or equal to zero, which is caused by the default contagion. This procedure keeps circulating until no bank defaults.

The third phase is the credit lending. We assume that there is a threshold $\left(\bar{M}_{k}(t)\right)$ of liquid assets for bank $k$ at time $t$, which guarantees the continuance of regular business operations, and $\bar{M}_{k}(t)=\theta T A_{k}(t)$. For a bank with positive net worth, it is a potential borrower if its liquid assets are less than the threshold; otherwise it is a potential lender. The demand or supply of liquidity for a bank is equal to $\mid M_{k}(t)-$ $\bar{M}_{k}(t) \mid$. From time $t=1$, in every period, we assume that there exists a potential interbank network; namely, potential borrowers can only borrow money from potential lenders who have links with them. If the potential borrower does not obtain enough liquidity from the first randomly selected potential lender, it contacts other potential banks for the remaining funds until its total demand for liquidity is satisfied or there is no more liquidity to be allocated. For the potential lender, if the total amount of demand for liquidity received from potential borrowers is less than its loanable liquidity, all its potential borrowers' demands for liquidity can be satisfied. Otherwise, the potential lender satisfies its potential borrowers in a sequence according to the rank of their net worth from high to low until all its loanable liquidity is completely allocated.

In this paper, we assume that the funds do not transfer from lenders to borrowers until borrowers' demand for liquidity is satisfied. Banks' balance sheets will be updated according to the actual borrowing or lending. If potential borrowers' demand for liquidity is not satisfied, they default. For the sake of simplicity, the total number of banks in the banking system is constant over time. Therefore, in this paper, we assume a simple mechanism of entry-exit: a default bank is replaced by a new one. The balance sheet structure of the new bank is the same as the initial balance sheet structure of the default bank. This can be interpreted as the entry of new banks into the interbank market. In fact, this mechanism is present in the existing literature, such as the study of Gatti et al. [30]. 
TABLE 1: Benchmark parameters of the model.

\begin{tabular}{llcc}
\hline Parameter & Description & Benchmark value & Range of variation \\
\hline$N$ & Number of banks & 100 & Positive integer \\
{$\left[A_{\min }, A_{\max }\right]$} & Range of values of initial assets & {$[5,200]$} & $0<A_{\min }<A_{\max }$ \\
$\tau$ & Pareto distribution parameter & 1.2 & Positive number \\
$\alpha$ & Initial proportion of investments & 0.9 & $(0,1)$ \\
$\beta$ & Initial proportion of net worth & 0.08 & $(0,1)$ \\
$\theta$ & Proportion of $\bar{M}_{k}(t)$ to $T A_{k}(t)$ & 0.08 & $(0,1)$ \\
$\eta$ & Interest rate parameter & 0.01 & Positive number \\
$\gamma$ & Scaling parameter for the level of deposit fluctuations & 0.1 & Positive number \\
$P_{1}$ & Probability of connection between any two nodes in random networks & 0.3 & 30 \\
$K$ & Number of nearest neighbors of a node in small-world networks & $30,1]$ \\
$P_{2}$ & Probability of randomly rewiring each edge of the lattice for small-world networks & 0.01 & Positive integer \\
$\xi$ & Initial number of nodes in scale-free networks & 25 & Positive integer \\
$\zeta$ & Number of edges of a new node in scale-free networks & 15 & Positive integer \\
\hline
\end{tabular}

2.2. Network Entropy. According to the above modeling of dynamic banking systems, we can obtain dynamic interbank networks, which can be represented by adjacency matrix $A(t)=\left(a_{i j}(t)\right)_{1 \leq i, j \leq N} \cdot a_{i j}(t)$ denotes the liability of bank $j$ towards bank $i$ at time $t$. In order to apply the concept of entropy, we need to transform adjacency matrices into stochastic matrices. Demetrius and Manke [31] propose the analysis of the stochastic matrix in the context of network robustness. In this paper, we adopt their method to define network entropy for dynamic banking systems. According to the adjacency matrix $A(t)$, we can obtain a stochastic matrix $\left(p_{i j}(t)\right)$ from the following formula [23]:

$$
p_{i j}(t)=\frac{a_{i j}(t)}{\sum_{j=1}^{N} a_{i j}(t)} .
$$

Given a stochastic matrix $\left(p_{i j}(t)\right)$, we apply the Shannon entropy formula [32] to the transition probability distribution which corresponds to the $i$ th row of the stochastic matrix, and we can obtain Shannon entropy $\left(E_{i}(t)\right)$ of node $i$ at time $t$, which is given as follows:

$$
E_{i}(t)=-\sum_{j=1}^{N} p_{i j}(t) \log p_{i j}(t)
$$

Moreover, we can obtain Shannon entropy $(E(t))$ of the interbank network at time $t$, which is defined as the weighted sum of entropies of nodes and is given as

$$
E(t)=\sum_{i=1}^{N} \pi_{i}(t) E_{i}(t),
$$

where $\pi_{i}(t)$ is the $i$ th component of the unique invariant distribution of the corresponding stochastic matrix $\left(p_{i j}(t)\right)$.

\section{Simulation Results}

According to the studies [2-4], we analyze network entropies in three kinds of potential interbank networks, namely, random networks, small-world networks, and scale-free networks. According to the algorithms provided by Erdös and Rényi [33], Watts and Strogatz [34], and Barabási and Albert [35], we construct the three kinds of potential interbank networks. Following the study of Lux [27], we assume that the initial total assets of all banks are drawn from a truncated Pareto distribution over the range $\left[A_{\min }, A_{\max }\right]$ with the power-law parameter $\tau$. Referring to the studies [27-29], we set the parameter values in Table 1. If not stated otherwise, our numerical simulations are performed with the parameters given in Table 1. For each set of parameters, we repeat every simulation 100 times to average out stochastic effects.

3.1. Network Entropy and Systemic Risk. Demetrius and Manke [31] study the process of network disintegration under random node removal for the three types of networks with different topological entropies and find that network entropy is positively correlated with robustness, where networks analyzed include scale-free networks, random networks, and regular networks. In the study of Demetrius and Manke [31], robustness pertains to the insensitivity of measurable parameters of the system to changes in its internal organization and includes dynamical robustness and topological robustness. Now we investigate whether network entropy can be used as a measure of robustness for banking systems from the perspective of systemic risk. In this paper, we adopt the number of default banks $(S)$ to measure the effect of systemic risk. Figure 1 shows the results of network entropies and the effects of systemic risk, where (a), (b), and (c) correspond, respectively, to the results of random, small-world, and scalefree networks. From Figure 1, it can be seen that the change trend of network entropies is similar to that of systemic risk.

Moreover, we adopt Pearson's correlation to investigate the correlation between network entropies and the effects of systemic risk. Table 2 shows Pearson's correlation coefficients between network entropies and the effects of systemic risk under different parameter values. We can observe that network entropy is positively correlated with the effect of systemic risk in the three kinds of interbank networks. Therefore, we provide computational and analytical support 


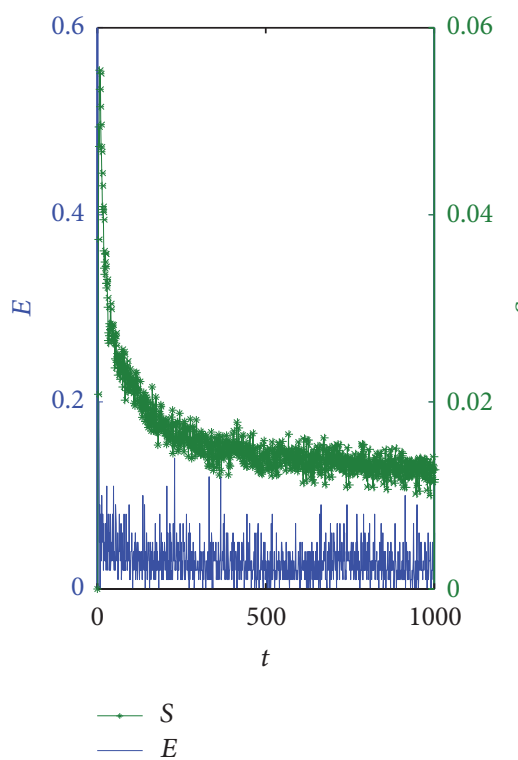

(a)

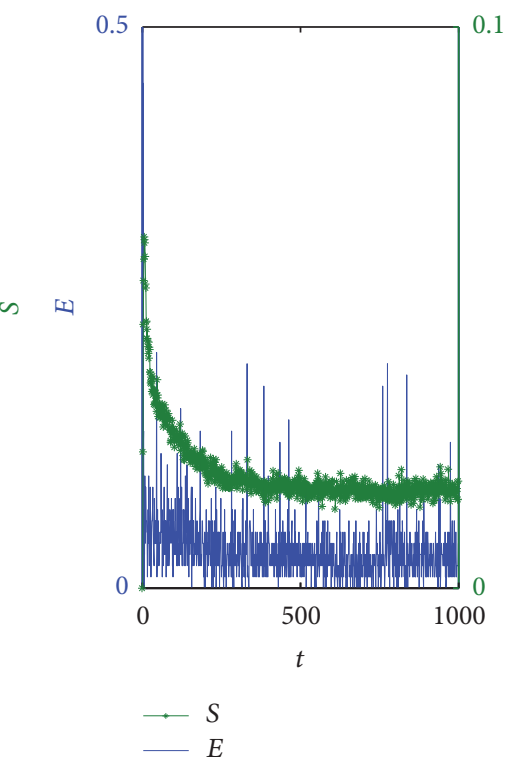

(b)

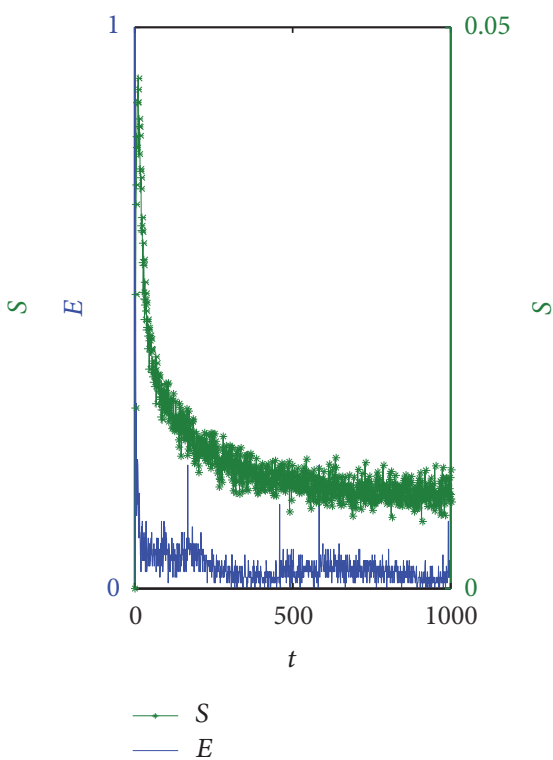

(c)

FIGURE 1: Network entropies and effects of systemic risk. (a), (b), and (c) correspond, respectively, to the results of random, small-world, and scale-free networks.

TABLE 2: Pearson's correlation coefficients between network entropies and systemic risk.

\begin{tabular}{lccc}
\hline Parameter & Random network & Small-world network & Scale-free network \\
\hline$\gamma_{k}=0.1$ & 0.3077 & 0.2729 & 0.5523 \\
$\gamma_{k}=0.2$ & 0.3108 & 0.3236 & 0.5508 \\
$\gamma_{k}=0.3$ & 0.1992 & 0.2845 & 0.5119 \\
$\bar{M}_{k}=0.06$ & 0.2556 & 0.2934 & 0.4834 \\
$\bar{M}_{k}=0.08$ & 0.3077 & 0.2729 & 0.5523 \\
$\bar{M}_{k}=0.1$ & 0.2922 & 0.3176 & 0.5516 \\
$\tau=1.2$ & 0.3077 & 0.2729 & 0.5523 \\
$\tau=2$ & 0.3098 & 0.2106 & 0.4747 \\
$\tau=3$ & 0.2644 & 0.1734 & 0.4688 \\
\hline
\end{tabular}

for that network entropy which can reflect the robustness of banking systems against systemic risk to a certain extent. Moreover, the network entropy can predict the direction of changes of systemic risk and characterize the stable states of dynamic banking systems.

3.2. Network Entropy and Network Structure. We now investigate the difference of network entropies in the three kinds of interbank networks. Figure 2 shows the network entropies in the random network, the small-world network, and the scalefree network. We can see that the values of network entropies present a trend of decrease after the increase, and they tend to be stable with time evolution. In fact, from Figure 1, we know that the effect of systemic risk has the same change trend as network entropies. Moreover, bank defaults change interbank network structures and then result in the above evolution characteristics of network entropies. Besides, we can observe that the value of network entropy in the small-world network is the largest among the three kinds of interbank networks, followed by those in random and scale-free networks.

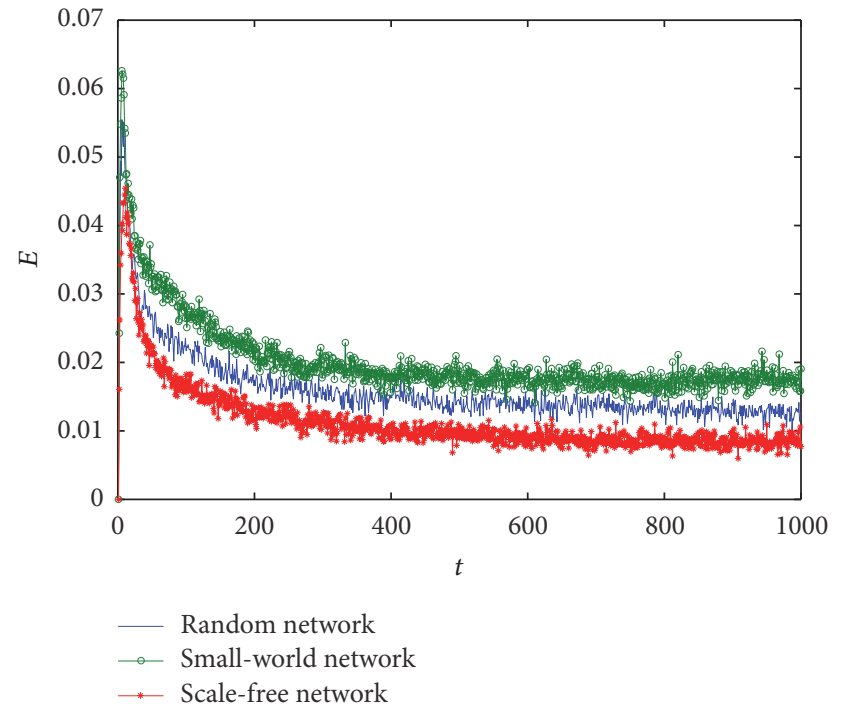

FIGURE 2: Network entropies in the three kinds of interbank networks. 


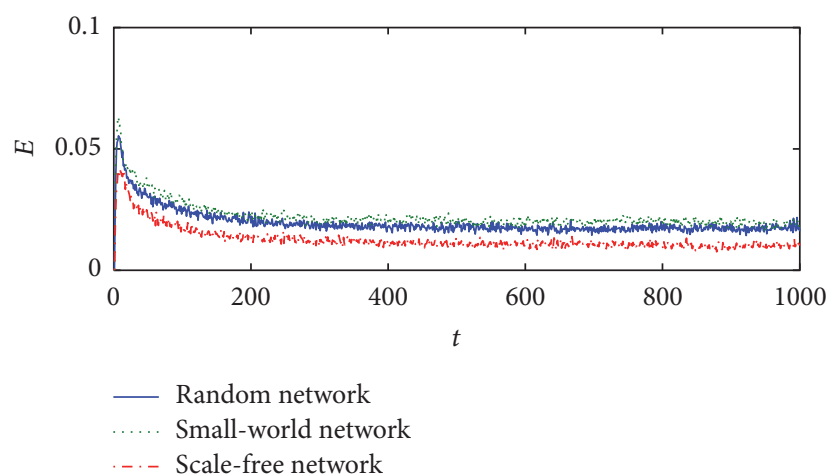

(a)

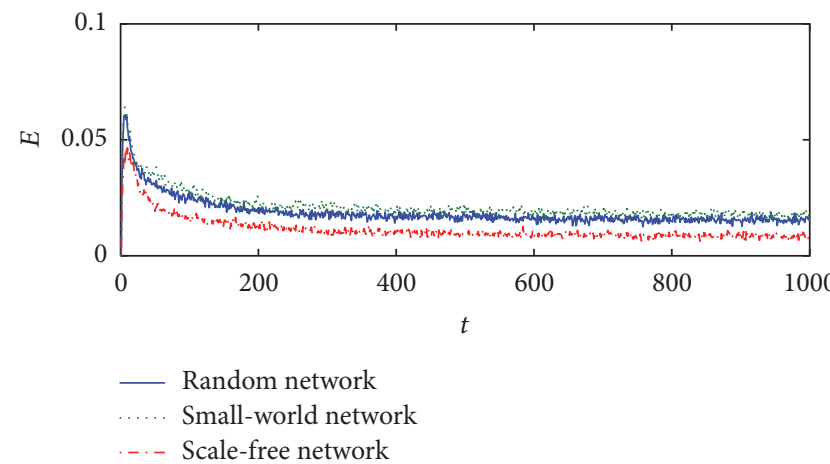

(c)

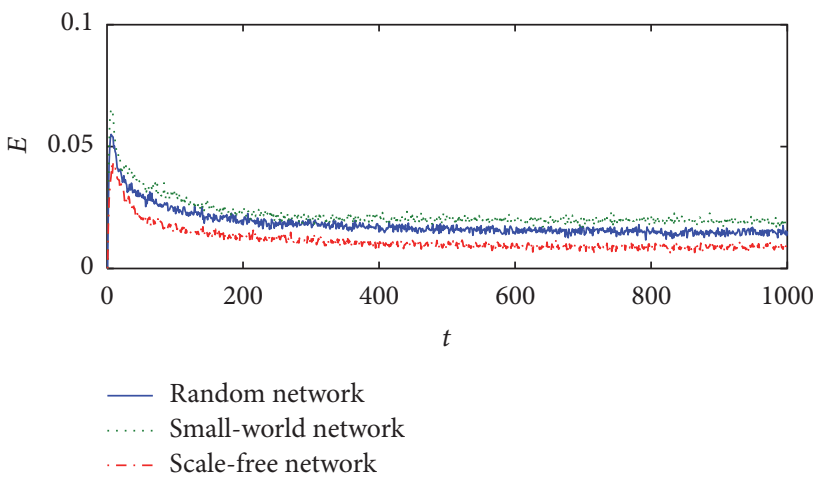

(e)

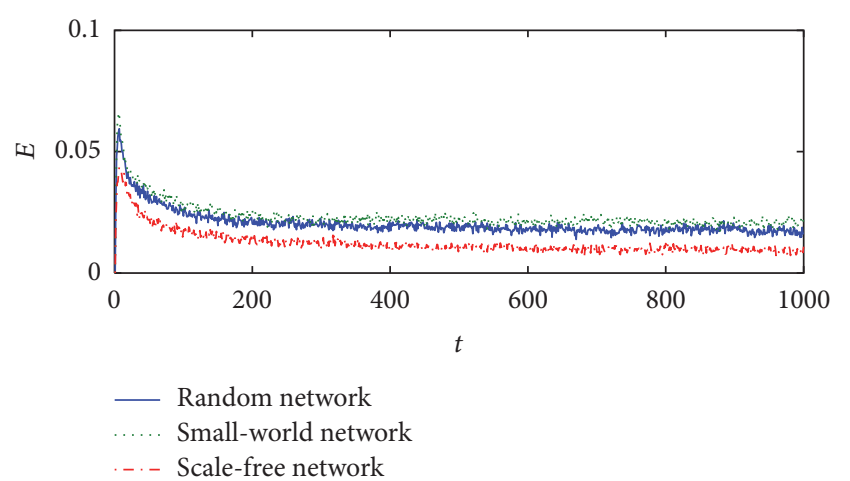

(b)

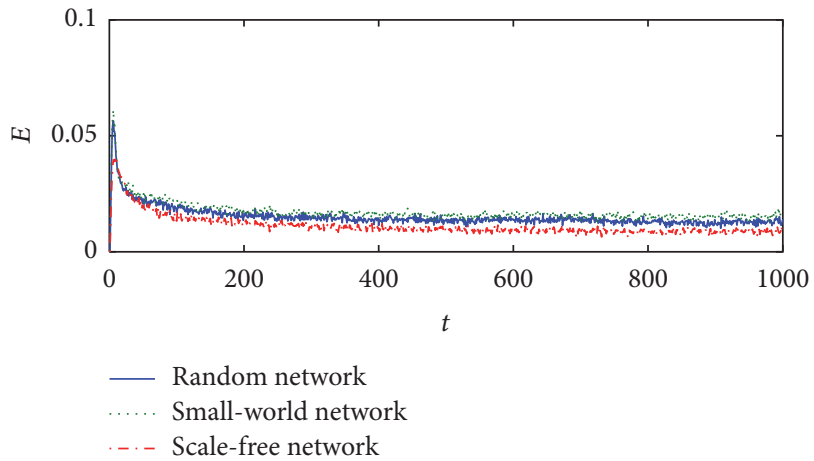

(d)



(f)

FiguRE 3: Network entropies in the three kinds of interbank networks under different parameter values. (a)-(f) are the results when $\gamma_{k}=0.2$, $\gamma_{k}=0.3, \bar{M}_{k}=0.06, \bar{M}_{k}=0.1, \tau=2$, and $\tau=3$, respectively.

According to the above model, we can see that $\gamma_{k}, \bar{M}_{k}$, and $\tau$ are the key parameters in the establishment of interbank networks. Therefore, we investigate the effect of these parameters on the above results, which is shown in Figure 3. We can observe that the above results do not change, despite the fact that the values of the parameters are different. From Figure 3, it can be seen that the network entropy trajectories are very similar among completely different network structures, and this similarity holds if we change some parameters. The probable reason for this result is that the effects of systemic risk are similar among different network structures.

\section{Conclusions}

In this paper, we first construct artificial banking systems and then investigate network entropy of dynamic banking systems, where the three kinds of potential interbank networks are analyzed, namely, random networks, small-world networks, and scale-free networks. First, simulation analysis shows that the change trend of network entropies is similar to that of systemic risk and that network entropy is positively correlated with the effect of systemic risk in the three kinds of interbank networks. Besides, we find that the value of network entropy in the small-world network is the largest 
among the three kinds of interbank networks, followed by those in random and scale-free networks.

In this paper, we analyze the network entropy in known network topologies. However, several works in the systemic risk and banking literatures show that financial networks are organized in a core-periphery structure. Therefore, we believe that more research needs to be done in order to understand how network entropy behaves in financial networks. For example, how does network entropy behave in coreperiphery structures? Moreover, is the entropy dependent on the network core size? Or does it show the same pattern regardless of the periphery and core sizes? Similar to most of the literature in this field, we define systemic risk as the number of defaulting banks. In the future, we would consider the total loss of capitalization of the banking system as a robustness indicator.

\section{Conflicts of Interest}

The authors declare that they have no conflicts of interest.

\section{Acknowledgments}

This research is supported by NSFC (no. 71201023, no. 71371051, and no. 71671037), Social Science Fund Project of Jiangsu Province (no. 15GLC003), Humanities and Social Science Planning Foundation of the Ministry of Education of China (no. 16YJA630026), and Teaching and Research Program for Excellent Young Teachers of Southeast University (no. 2242015R30021).

\section{References}

[1] R. Gençay, D. Signori, Y. Xue, X. Yu, and K. Zhang, "Economic links and credit spreads," Journal of Banking \& Finance, vol. 55, pp. 157-169, 2015.

[2] M. Boss, H. Elsinger, M. Summer, and S. Thurner, "Network topology of the interbank market," Quantitative Finance, vol. 4, no. 6, pp. 677-684, 2004.

[3] K. Soramäki, M. L. Bech, J. Arnold, R. J. Glass, and W. E. Beyeler, "The topology of interbank payment flows," Physica A: Statistical Mechanics and its Applications, vol. 379, no. 1, pp. 317333, 2007.

[4] G. Iori, G. De Masi, O. V. Precup, G. Gabbi, and G. Caldarelli, "A network analysis of the Italian overnight money market," Journal of Economic Dynamics and Control (JEDC), vol. 32, no. 1, pp. 259-278, 2008.

[5] P. E. Mistrulli, "Assessing financial contagion in the interbank market: maximum entropy versus observed interbank lending patterns," Journal of Banking \& Finance, vol. 35, no. 5, pp. 11141127, 2011.

[6] L. M. M. Fernandes and M. R. Borges, "Interbank linkages and contagion risk in the Portuguese banking system," ISEG/DE Working Papers, 2013.

[7] G. Hałaj and C. Kok, "Assessing interbank contagion using simulated networks," Computational Management Science, vol. 10, no. 2-3, pp. 157-186, 2013.

[8] E. Batiz-Zuk, F. López-Gallo, S. Martínez-Jaramillo, and J. P. Solórzano-Margain, "Calibrating limits for large interbank exposures from a system-wide perspective," Journal of Financial Stability, vol. 27, pp. 198-216, 2016.
[9] G. Hałaj and C. Kok, "Modelling the emergence of the interbank networks," Quantitative Finance, vol. 15, no. 4, pp. 653-671, 2015.

[10] A. Gandy and L. A. Veraart, "A bayesian methodology for systemic risk assessment in financial networks," SSRN Electronic Journal, article 2580869, 2015.

[11] T. Chen, X. Li, and J. Wang, "Spatial interaction model of credit risk contagion in the CRT market," Computational Economics, vol. 46, no. 4, pp. 519-537, 2015.

[12] P. Glasserman and H. P. Young, "Contagion in financial networks," Journal of Economic Literature (JEL), vol. 54, no. 3, pp. 779-831, 2016.

[13] S. Langfield and K. Soramäki, "Interbank Exposure Networks," Computational Economics, vol. 47, no. 1, pp. 3-17, 2016.

[14] S. Li and X. Sui, "Contagion risk in endogenous financial networks," Chaos, Solitons \& Fractals, vol. 91, pp. 591-597, 2016.

[15] A. Sensoy, "Systematic Risk in Conventional and Islamic Equity Markets," International Review of Finance, vol. 16, no. 3, pp. 457466, 2016.

[16] T. C. Silva, M. S. da Silva, and B. M. Tabak, "Financial networks and bank liquidity," The Journal of Network Theory in Finance, vol. 2, no. 4, pp. 1-51, 2016.

[17] T. C. Silva, S. R. S. de Souza, and B. M. Tabak, "Network structure analysis of the Brazilian interbank market," Emerging Markets Review, vol. 26, pp. 130-152, 2016.

[18] T. C. Silva, S. M. Guerra, B. M. Tabak, and R. C. de Castro Miranda, "Financial networks, bank efficiency and risk-taking," Journal of Financial Stability, vol. 25, pp. 247-257, 2016.

[19] T. C. Silva, S. R. Souza, and B. M. Tabak, "Monitoring vulnerability and impact diffusion in financial networks," Journal of Economic Dynamics \& Control, vol. 76, pp. 109-135, 2017.

[20] M. Dehmer, "Information processing in complex networks: graph entropy and information functionals," Applied Mathematics and Computation, vol. 201, no. 1-2, pp. 82-94, 2008.

[21] K. Anand and G. Bianconi, "Entropy measures for networks: toward an information theory of complex topologies," Physical Review E: Statistical, Nonlinear, and Soft Matter Physics, vol. 80, no. 4, article 045102, 2009.

[22] T. Nie, Z. Guo, K. Zhao, and Z.-M. Lu, "Using mapping entropy to identify node centrality in complex networks," Physica A: Statistical Mechanics and its Applications, vol. 453, pp. 290-297, 2016.

[23] D. Lee, "Entropy of global financial linkages," Bank of Korea WP 2014-30, 2014.

[24] L. Alessi and C. Detken, "Quasi real time early warning indicators for costly asset price boom/bust cycles: A role for global liquidity," European Journal of Political Economy, vol. 27, no. 3, pp. 520-533, 2011.

[25] M. Billio, R. Casarin, M. Costola, and A. Pasqualini, "An entropy-based early warning indicator for systemic risk," Journal of International Financial Markets, Institutions and Money, vol. 45, pp. 42-59, 2016.

[26] M. Cai, Y. Cui, and H. E. Stanley, "Analysis and evaluation of the entropy indices of a static network structure," Scientific Reports, vol. 7, no. 1, article 9340, 2017.

[27] T. Lux, "Emergence of a core-periphery structure in a simple dynamic model of the interbank market," Journal of Economic Dynamics \& Control, vol. 52, pp. A11-A23, 2015.

[28] D. Gatti, M. Gallegati, B. Greenwald, A. Russo, and J. E. Stiglitz, "The financial accelerator in an evolving credit network," Journal of Economic Dynamics \& Control, vol. 34, no. 9, pp. 16271650, 2010. 
[29] C.-P. Georg, "The effect of the interbank network structure on contagion and common shocks," Journal of Banking \& Finance, vol. 37, no. 7, pp. 2216-2228, 2013.

[30] D. D. Gatti, M. Gallegati, B. C. Greenwald, A. Russo, and J. E. Stiglitz, "Business fluctuations and bankruptcy avalanches in an evolving network economy," Journal of Economic Interaction and Coordination, vol. 4, no. 2, pp. 195-212, 2009.

[31] L. Demetrius and T. Manke, "Robustness and network evolution - An entropic principle," Physica A: Statistical Mechanics and its Applications, vol. 346, no. 3-4, pp. 682-696, 2005.

[32] C. E. Shannon and W. Weaver, The Mathematical Theory of Communication, The University of Illinois Press, Urbana, Ill, USA, 1949.

[33] P. Erdös and A. Rényi, "On random graphs," Publicationes Mathematicae, vol. 6, pp. 290-297, 1959.

[34] D. J. Watts and S. H. Strogatz, "Collective dynamics of 'smallworld' networks," Nature, vol. 393, no. 6684, pp. 440-442, 1998.

[35] A.-L. Barabási and R. Albert, "Emergence of scaling in random networks," American Association for the Advancement of Science: Science, vol. 286, no. 5439, pp. 509-512, 1999. 


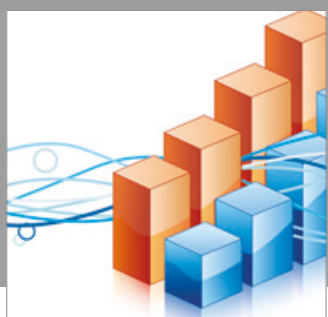

Advances in

Operations Research

vatersals

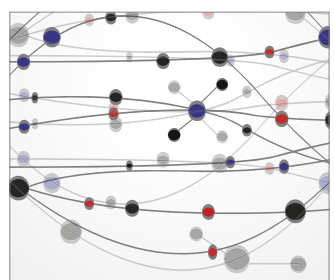

\section{The Scientific} World Journal
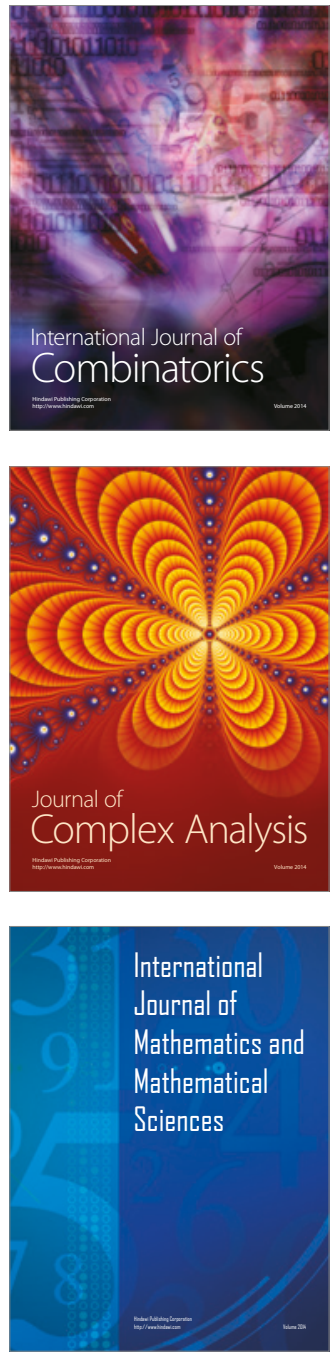
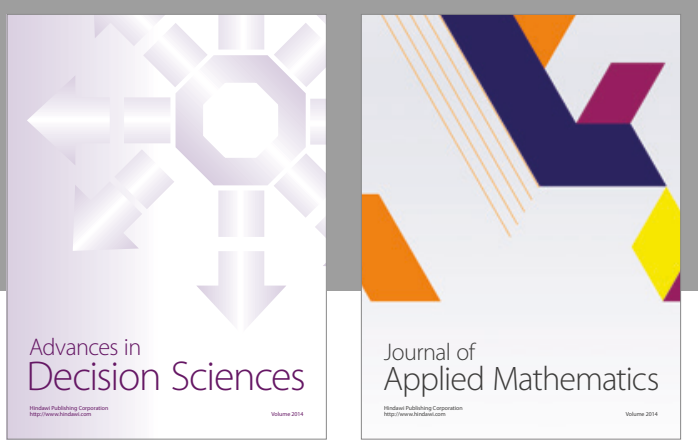

Algebra

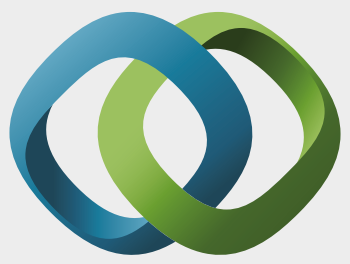

\section{Hindawi}

Submit your manuscripts at

https://www.hindawi.com
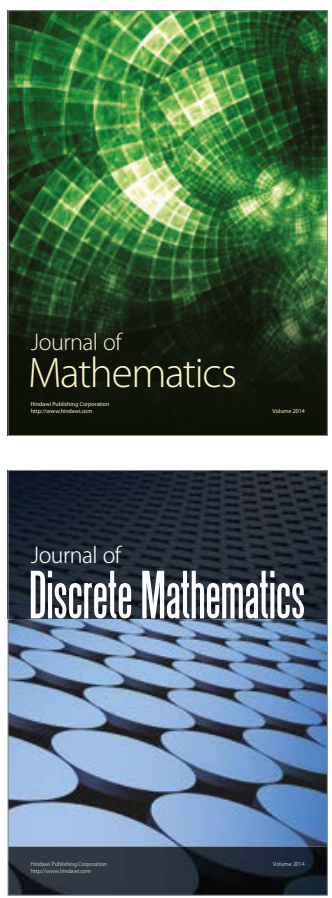

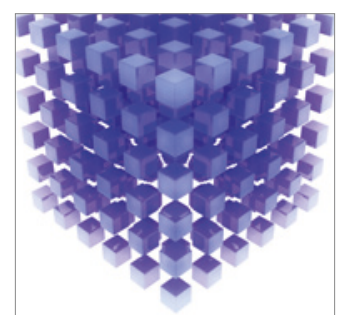

Mathematical Problems in Engineering


Journal of

Function Spaces

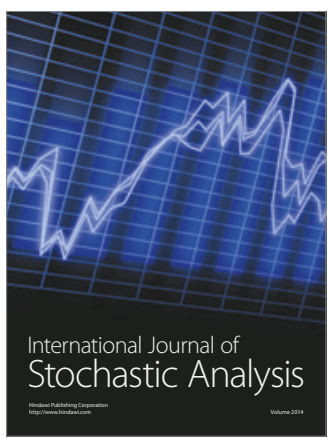

Probability and Statistics
